\title{
Determinants of each domain of the Short Physical Performance Battery in COPD
}

\author{
This article was published in the following Dove Press journal: \\ International Journal of COPD \\ 23 August 2017 \\ Number of times this article has been viewed
}

\author{
Roberto Bernabeu-Mora' \\ Luz M Giménez-Giménez ${ }^{2}$ \\ Joaquina Montilla- \\ Herrador ${ }^{2}$ \\ Gloria García-Guillamón ${ }^{2}$ \\ José Antonio García-Vidal² \\ Francesc Medina-Mirapeix ${ }^{2}$ \\ 'Division of Pneumology, Hospital \\ General Universitario Morales \\ Meseguer, ${ }^{2}$ Department of Physical \\ Therapy, University of Murcia, \\ Murcia, Spain
}

\begin{abstract}
Background: The Short Physical Performance Battery (SPPB) is an assessment tool with good prognostic value in COPD. It includes the following: standing balance, $4 \mathrm{~m}$ gait speed test (4MGS), and the timed five-repetition sit-to-stand test (5STS). The specific differences in determinants between these three tasks have not been adequately characterized in COPD patients. We aimed to identify health-related, functional, and psychological determinants of each SPPB test.

Methods: We conducted a cross-sectional analysis of 137 patients with stable COPD. Patients performed the SPPB, quadriceps muscle strength (QMS), exercise tolerance test (6-min walk test $[6 \mathrm{MWT}]$ ), and pulmonary function; and health-related and psychological factors, physical activity, the COPD assessment test (CAT), body mass index, age, and depression were assessed.

Results: Separate multivariable regression models predicting the 4MGS, 5STS, and balance test results described $31 \%, 39.1 \%$, and $12.1 \%$ of the variance for each test, respectively. QMS was negatively associated with all three tests. The 6MWT was negatively associated with the 4MGS and 5STS. Depression and age were positively associated with 4MGS scores, whereas CAT and age were positively associated with 5STS scores.

Conclusion: The three SPPB tests did not provide equivalent information regarding a COPD patient's status. The 5STS was associated with health status factors, while the 4MGS was associated with psychological factors.
\end{abstract}

Keywords: COPD, muscle strength, gait speed, 6-min walk test, depression

\section{Introduction}

The Short Physical Performance Battery (SPPB) is one of the most commonly used tools for measuring physical performance in various populations, including patients with COPD. ${ }^{1-3}$ The SPPB comprises three functional tasks: a hierarchical standing balance task, assessment of a short walk at normal speed with the $4 \mathrm{~m}$ gait speed test (4MGS), and evaluation of ability to stand from a chair with the five-repetition sit-tostand test (5STS). SPPB scores can describe a hierarchy, from high-level functioning to severe deterioration of lower extremity function, with higher scores indicating better lower body function. ${ }^{4}$

Low SPPB scores in elderly people have a strong predictive value for a wide range of health consequences, including disability in activities of daily living (ADL), 5,6 mobility loss, ${ }^{7}$ disability, ${ }^{5,8}$ hospitalization, ${ }^{9}$ duration of hospital stay, ${ }^{10}$ admission to nursing facilities, ${ }^{8}$ and death. ${ }^{11-14}$ In COPD patients, the SPPB summary score is useful for predicting disability. ${ }^{15,16}$ Scores on the 4MGS and 5STS alone can also predict $^{17-19}$ poor exercise capacity ${ }^{20}$ and mortality ${ }^{21}$ in COPD patients. Changes over time in these tests also show predictive ability. ${ }^{22}$ In particular, reduced gait speed over time in cases of severe COPD may herald short-term mortality. ${ }^{22,23}$ For these reasons,

\footnotetext{
Correspondence: Roberto

Bernabeu-Mora

Division of Pneumology, Hospital

General Universitario Morales Meseguer,

Avda Marqués de los Velez s/n,

30008 Murcia, Spain

Tel +34968360900

$\mathrm{Fax}+34968360994$

Email rbernabeumora@hotmail.com
}

(c) (1) (-) 2017 Bernabeu-Mora et al. This work is published and licensed by Dove Medical Press Limited. The full terms of this license are available at https://www.dovepress.com/terms.php cC) and incorporate the Creative Commons Attribution - Non Commercial (unported, v3.0) License (http://creativecommons.org/licenses/by-nc/3.0/). By accessing the work you hereby accept the Terms. Non-commercial uses of the work are permitted without any further permission from Dove Medical Press Limited, provided the work is properly attributed. For permission for commercial use of this work, please see paragraphs 4.2 and 5 of our Terms (https://www.dovepress.com/terms.php). 
screening adults through the 4MGS, the 5STS, or the SPPB has been regarded in many clinical settings. What is less clear is when one should use each individual test of the SPPB or the whole of SPPB. In a previous study, we did comparisons between the three tests for the purpose of establishing validity and highlighting their similarities as measures that could identify patients with mobility limitations. ${ }^{19}$ However, to our knowledge, no study has compared these three types of functional tests with respect to the types of physiological and psychosocial factors that may be associated with each measure in COPD patients.

Some authors have investigated why some COPD patients perform poorly on this battery ${ }^{24}$ or on the $4 \mathrm{MGS} .{ }^{20}$ Quadriceps muscle strength (QMS) and exercise capacity are reportedly two of the more important determinants of the SPPB summary score. ${ }^{24}$ Exercise capacity is also cited as a relevant determinant of normal gait speed in cases of COPD. ${ }^{20}$ The 4MGS score is reportedly associated with age and cognitive dysfunction (ie, depression). ${ }^{20}$ Thus, the 4MGS appears to be an integrative test that reflects both the functional and psychosocial capabilities of patients with COPD. ${ }^{25}$

It is not yet known whether the three SPPB domains are influenced by similar factors or if each test has different determinants. Moreover, while some factors have been identified as relevant for the $4 \mathrm{MGS}$ score, ${ }^{20}$ the importance of QMS for the 4MGS remains to be elucidated. The present study aimed to identify the determinants of each test of the SPPB when conducted in patients with clinically stable COPD. We hypothesized that similar functional and health-related factors would be associated with the 4MGS and 5STS tests, but that gait speed would additionally be associated with psychological factors, such as depression. We also hypothesized that the balance test would only be associated with functional factors related to neuromusculoskeletal systems, such as QMS.

\section{Methods}

\section{Study design and participants}

We performed a controlled cross-sectional study of patients with stable COPD who were prospectively recruited from an outpatient pulmonary service at Meseguer Hospital, Murcia, Spain. All study participants provided written informed consent, and the study protocol was approved by the institutional review board of the hospital called "Comité Ético de Investigación Clínica del Hospital General Universitario José María Morales Meseguer" (EST-35/13).

Inclusion criteria were COPD diagnosis, a ratio of forced expiratory volume in $1 \mathrm{~s}\left(\mathrm{FEV}_{1}\right) /$ forced vital capacity that was $<70 \%$ of the predicted value, and age of $40-80$ years. COPD diagnosis and the disease severity stage were based on the Global Initiative for Chronic Obstructive Lung Disease (GOLD) guidelines. ${ }^{26}$ Patients were excluded if they had an unstable cardiac condition within 4 months prior to the study, cognitive deterioration, or limited walking ability. Based on patient health examinations, we identified a consecutive sample of eligible patients during a 1-year period. Potential participants were assessed for eligibility criteria by a pulmonary physician. Our study sample included 137 patients.

\section{Measures}

All participants were asked to perform the SPPB. The participants also underwent tests to evaluate potential functional (quadriceps strength, exercise tolerance, and pulmonary function), health-related (dyspnea, health status, body mass index [BMI], and age), and psychological factors (presence of depression symptoms). These factors were selected for evaluation based on the available literature and their clinical associations with the SPPB summary score or any of its domains. ${ }^{20,21,24}$ Data reported in this article were collected from the same subjects as part of a previously published study. ${ }^{19}$

\section{Physical performance tests}

Patients performed the SPPB subscale tests following the protocols of the National Institute on Aging. ${ }^{4}$ For the 4MGS test, tape was used to mark out $4 \mathrm{~m}$ on a flat unobstructed course within a clinical assessment room. Prior to starting the test, the participants viewed a demonstration of the walk but did not perform a practice walk themselves. The participant was positioned with their toes just touching the start line. Timing began when the participant first started moving and was stopped when the participant's first foot completely crossed the $4 \mathrm{~m}$ line. Timing lower than $4.8 \mathrm{~s}$ was considered no impairment.

In the 5STS test, we measured the time taken to complete five repetitions of the sit-to-stand maneuver. All sit-to-stand maneuvers were performed in a chair without an armrest, with a height of $43 \mathrm{~cm}$ and a depth of $47.5 \mathrm{~cm}$. Timing began when the subject's back left the backrest and stopped once the back touched the backrest for the fifth time. Timing lower than $11.2 \mathrm{~s}$ was considered no impairment.

Finally, the standing balance measurement required that participants maintain three stances for $10 \mathrm{~s}$ each: side-by-side, semitandem, and tandem. The possible scores ranged from 0 (null balance) to 4 (no balance impairment). 


\section{Functional factors}

QMS was measured with a dynamometer, following reliable and valid methods. ${ }^{27}$ Exercise tolerance was measured using the 6-min walk test (6MWT), which was performed on a flat, straight, indoor, $30 \mathrm{~m}$ walking course, supervised by well-trained hospital staff following the ATS guidelines. ${ }^{28}$ Flow-volume spirometry was assessed using a MasterScope spirometer, software version 4.6 (Jaeger GmbH, Wurzburg, Germany) following the guidelines of the European Respiratory Society. ${ }^{29}$ The percentage of predicted pulmonary function values was calculated using predictive equations derived from Castellsagué et al. ${ }^{30}$

\section{Health-related and psychological factors}

Dyspnea was measured using the modified Medical Research Council (mMRC) dyspnea score ${ }^{31}$ and health status with the COPD assessment test (CAT). ${ }^{32}$ A CAT score of $\geq 10$ and an $\mathrm{mMRC}$ of $\geq 2$ are considered clinically poor. ${ }^{32,33}$ Physical activity was measured using the Spanish Short Version of the Minnesota Leisure Time Physical Activity Questionnaire (VREM) ${ }^{34}$ Height and weight were evaluated using a calibrated scale and stadiometer. BMI was calculated as mass $(\mathrm{kg}) /$ height $(\mathrm{m})^{2}$. Presence of depressive symptoms was assessed using the depression scale of the Hospital Anxiety and Depression Scale (HADS) ${ }^{35}$ The HADS score can range from 0 to 21 points. Here, we used binary categories, applying an accepted cutoff of $8 / 21$ for depression. ${ }^{36}$

\section{Statistical analysis}

All analyses were performed using the SPSS statistical software program, version 19.0 (IBM SPSS, Chicago, IL, USA). We calculated descriptive statistics - including frequencies and proportions for categorical variables, and mean values and SDs for continuous variables. Univariate and multivariate regression models were used to assess associations between the evaluated factors and each SPPB test. We created linear models for tests measured in seconds (4MGS and 5STS), and logistic regression models to identify impairment in the balance test (score $<4$ ). In univariate analyses, associations were tested for significant relationships with each SPPB test. All models were produced using the enter method. The variables that showed a statistically significant association $(P<0.10)$ with the 4MGS and 5STS scores were entered in a stepwise multivariate linear model, whereas those associated with the balance test were entered in a forward logistic regression model. All methods used a criterion of $P<0.05$ for model inclusion. Sample size calculation was based on the general rule that 15 subjects per predictor are needed for a reliable equation. ${ }^{37} \mathrm{We}$ recruited a minimum of 120 participants, assuming a maximum of eight predictors.

\section{Results}

Among the 147 initially enrolled patients with COPD, 10 did not meet the inclusion criteria. Therefore, a total of 137 patients were included. Three values were missing at baseline (2.18\%), only for the 6MWT. Table 1 presents patient characteristics. The mean participant age was 66.9 years and $87.6 \%$ were male. The average times to perform the 4MGS and 5SST were $4.7 \pm 2.7 \mathrm{~s}$ and $14.2 \pm 3.2 \mathrm{~s}$, respectively. The mean balance subscale score was $3.7 \pm 0.7$, and 29 patients $(21.2 \%)$ showed balance impairment (score $<4$ ).

As a result of the univariate analyses, a total of six significant variables (age, QMS, 6MWT, CAT, dyspnea, and HADS) were entered in the multivariate models of the 4MGS and the 5STS as well, but only four variables were retained in each final model (Table 2).

The multivariable models predicting performance on the 4MGS and the 5STS were statistically significant $(P<0.05)$, describing $31 \%$ and $39.1 \%$ of the variance $\left(\mathrm{R}^{2}\right)$, respectively (Table 2). The 4MGS score was negatively associated with QMS and exercise tolerance test result, which described $2.4 \%$ and $5.2 \%$ of the variance (partial $\mathrm{R}^{2}$ ), respectively. On the other hand, the 4MGS score was positively associated with age and presence of depression symptoms, which described $4.9 \%$ and $3.2 \%$ of the variance, respectively. The 5 STS score

Table I Descriptive characteristics

\begin{tabular}{lll}
\hline Descriptive characteristics & $\begin{array}{l}\text { Mean } \pm \text { SD or } \\
\text { number (\%) }\end{array}$ & Range \\
\hline Health-related & & \\
Age (years) & $66.9 \pm 8.3$ & $46-80$ \\
Dyspnea (mMRC) $\geq 2$ & $49(35.8)$ & N/A \\
BMI & $28.9 \pm 5.1$ & $16.7-46$ \\
Physical activity (METs/l4 days) & $4,206.8 \pm 5,285.6$ & $0-27,389.9$ \\
COPD assessment (CAT score) & $14.19 \pm 7.32$ & $1-39$ \\
Functional status & & \\
Pulmonary function (FEV $\%$ ) & $50.2 \pm 16.5$ & $17-102$ \\
Exercise tolerance (6MWT, m) & $349.1 \pm 84.7$ & $54-570$ \\
Quadriceps strength (kg) & $31.37 \pm 5.74$ & $17.9-44.9$ \\
Psychological status & & \\
HADS score (depression scale) $\geq 8$ & $26(19)$ & $\mathrm{N} / \mathrm{A}$ \\
SPPB subscales & & \\
5STS test (in seconds) & $14.2 \pm 3.2$ & $6.9-28.5$ \\
4MGS test (in seconds) & $4.7 \pm 2.7$ & $2.5-33$ \\
Balance test & $3.7 \pm 0.7$ & $0-4$ \\
\hline
\end{tabular}

Abbreviations: mMRC, modified Medical Research Council Dyspnea Scale; BMI, body mass index; METs, metabolic energy turnover; CAT, COPD assessment test; $\mathrm{FEV}_{1}$, forced expiratory volume in I s; 6MWT, 6-min walk test; HADS, Hospital Anxiety and Depression Scale; 5STS, five-repetition sit-to-stand; 4MGS, $4 \mathrm{~m}$ gait speed; SPPB, Short Physical Performance Battery; N/A, not applicable. 
Table 2 Final multivariable linear regression models

\begin{tabular}{llllllll}
\hline $\begin{array}{l}\text { Functional } \\
\text { measure }\end{array}$ & Independent variable & Estimate & $\begin{array}{l}\text { Standard } \\
\text { error }\end{array}$ & $\begin{array}{l}\text { B } \\
\text { standardized }\end{array}$ & P-value & Model R $^{2}$ & Partial R $^{2}$ \\
\hline 4MGS & Age (years) & 0.033 & 0.011 & 0.247 & 0.003 & 0.310 & 0.049 \\
& Exercise tolerance (6MWT, m) & -0.003 & 0.001 & -0.260 & 0.002 & 0.052 \\
& Quadriceps strength (kg) & -0.032 & 0.015 & -0.172 & 0.034 & 0.024 \\
& HADS >8 (depression scale) & 0.515 & 0.213 & 0.183 & 0.017 & 0.032 \\
5STS & Age (years) & 0.084 & 0.031 & 0.218 & 0.007 & 0.391 & 0.040 \\
& CAT score & 0.134 & 0.036 & 0.279 & 0.000 & 0.073 \\
& Exercise tolerance (6MWT, m) & -0.010 & 0.003 & -0.263 & 0.002 & 0.056 \\
& Quadriceps strength (kg) & -0.140 & 0.043 & -0.251 & 0.001 & 0.056 \\
\hline
\end{tabular}

Abbreviations: 6MWT, 6-min walk test; HADS, Hospital Anxiety and Depression Scale; CAT, COPD assessment test; 5STS, five-repetition sit-to-stand; 4MGS, $4 \mathrm{~m}$ gait speed.

was negatively associated with QMS and exercise tolerance test result, which both described $5.6 \%$ of the variance. The 5STS score was positively associated with age $(4.0 \%$ of the variance) and with CAT score, which described the highest percentage of the variance $(7.3 \%)$.

A total of four significant variables (age, QMS, 6MWT, and CAT) were entered in the multivariate model for the balance test, but only QMS was retained in the final model. This final model explained $12.1 \%$ of the variance (Nagelkerke $\mathrm{R}^{2}$ squared) and was significant: $\chi^{2}(1, \mathrm{~N}=137)=10.71$, $P<0.001$. The QMS showed an odds ratio of 0.88 (95\% confidence interval $=0.81$ to 0.95 ), indicating that every 1 -unit increase in QMS is related to a $12 \%$ decrease ( 1 to 0.88 ) in the odds of having balance impairment (score $<4$ ).

\section{Discussion}

Our present results revealed important similarities and differences between the three domains of the SPPB with respect to the factors associated with each test. Quadriceps strength was associated with all three dimensions of the SPPB, as was expected for a battery measuring lower-extremity function..$^{24,38}$ Numerous geriatrics studies have previously demonstrated the relevance of quadriceps strength in the three domains. ${ }^{39,40}$ Quadriceps strength is associated with deficits in balance ${ }^{41}$ and gait speed ${ }^{42}$ and has been described as extremely important for performing the movement required to enable functionally limited elders to arise from a chair. ${ }^{39,40}$

Notably, exercise tolerance was an important determinant of two SPPB components: gait speed and sit-to-stand ability. These findings are consistent with prior study results. ${ }^{21,25}$ The non-significant relationship between 6MWT and the balance component of the SPPB may be explained by the fact that successful balance maintenance is a complex skill that also relies on other determinants, such as the integration and coordination of musculoskeletal systems (ie, biomechanics, range of motion, and flexibility) and neural systems (ie, motor, sensory, and higher-level premotor processes). ${ }^{41,43}$
Exercise tolerance and QMS showed similar importance to 5STS determinants (eg, similar $\beta$ coefficient and $\mathrm{R}^{2}$ partial). In contrast, although quadriceps strength was a determinant of 4MGS results, exercise tolerance had greater relevance: $\beta=-0.263$ versus $\beta=-0.251$. While the sit-to-stand test clearly requires quadriceps strength, ${ }^{21}$ our data suggest that walking $4 \mathrm{~m}$ is more closely related to exercise tolerance than to muscle strength properties, which may explain why it appears that the 4MGS would make a better alternative to $6 \mathrm{MWT} .{ }^{25}$

Pulmonary function measured by $\mathrm{FEV}_{1}$ was not associated with any domain of the SPPB. The finding that pulmonary function was unrelated to the balance test is consistent with the results reported by Eisner et $\mathrm{al}^{44}$ and in other studies of balance in $\mathrm{COPD},{ }^{40}$ reinforcing that pulmonary function is not a determinant of balance deficits. However, our findings that pulmonary function was unrelated to the 4MGS and 5STS tests contradict the results reported by Eisner et al, ${ }^{44}$ which showed associations between $\mathrm{FEV}_{1}$ and the scores of these two tests. However, Eisner et a $\mathrm{l}^{44}$ used qualitative subscores (range of 0-4) of the tests, which likely mediated the influence of $\mathrm{FEV}_{1}$. Supporting this possible explanation, a previous study evaluating determinants of gait speed in meters per second also concluded that $\mathrm{FEV}_{1}$ is not a relevant determinant of this test. ${ }^{20}$

Interestingly, health status measured by CAT was associated with the 5STS but not with the other two SPPB tests, supporting the concept that the 5STS is a better screening tool for poor health status. One possible reason is that the sit-to-stand test poses greater ventilatory demands. ${ }^{21}$ While other proxy constructs of health status (eg, quality of life and physical mobility) have been related to the sit-to-stand test, to our knowledge, this is the first study to find an association between 5STS and health status measured by the CAT in COPD. Surprisingly, the multivariable model showed that dyspnea was not associated with any SPPB domain, which is in contrast to previous findings. ${ }^{20,21,41}$ It is possible 
that statistical significance was not achieved in the present study due to the adjustments made for confounding variables included in the multivariable models. For example, Karpman et $\mathrm{al}^{20}$ did not evaluate the influence of other measures of health status, such as CAT or QMS, which likely mediated the influence of dyspnea on gait speed.

Our results also showed that depression had a significant influence on gait speed, but not on the other SPPB tests, possibly reflecting the more complex construct of gait speed. ${ }^{25}$ Other authors have investigated the relationships of gait speed with mood and cognitive function. ${ }^{20}$ However, the presently observed significant multivariate association between psychological status and gait speed in COPD is novel.

\section{Limitations}

Our present investigation was conducted among patients recruited during health examinations at an outpatient pulmonary service, and only cross-sectional strategies were used to study the construct of each subscale. Futures studies should prospectively consider these associations and should include a broader range of locations. Additionally, our analyses of the balance test results were stratified according to a clinically relevant cutoff (balance impairment), which was not derived from previous studies. Finally, few patients in our study showed balance impairments (score $<4$ ). However, this does not pose a major problem regarding the validity of the presently tested logistic models using balance as a dependent variable, because the general rule of 10 events per predictor variable can be relaxed when that number is close to $10 . .^{45}$

\section{Implications for practice and research}

Our present findings provide empirical evidence suggesting that tests of the SPPB do not provide equivalent information regarding the status of a COPD patient. The observed similarities and differences between tests have a variety of implications in various situations in which one test might be selected. For example, if a clinician wants a screening tool to detect poor health status in COPD patients, the 5STS would appear to be the most suitable test. If a test is needed to assess outcome measures following an intervention aimed at improving psychological status, the $4 \mathrm{MGS}$ would be an exceptionally good choice. On the other hand, if an intervention relates to exercise tolerance and/or QMS, the 5STS test may be a more suitable functional outcome tool.

\section{Conclusion}

Our present results show that the three tests of the SPPB do not provide equivalent information regarding the status of a COPD patient and broaden our understanding of the role of the SPPB. Musculoskeletal functional factors were negatively associated with all tests. The 5STS was associated with health status factors, while the 4MGS was associated with psychological factors. Knowledge of these differences will be helpful to clinicians and researchers when considering the use of each test.

\section{Acknowledgments}

The authors wish to thank the patients and personnel of the hospital unit for their cooperation during the course of this study and the medical manager of AstraZeneca Pharmaceutical Spain, S.A. (Maite Pérez Hernández). The study was supported by AstraZeneca pharmaceutical Spain, S.A. Menarini and Pfizer.

\section{Disclosure}

The authors report no conflicts of interest in this work.

\section{References}

1. Guralnik JM, Ferrucci L, Simonsick EM, Salive ME, Wallace RB Lower-extremity function in persons over the age of 70 years as a predictor of subsequent disability. N Engl J Med. 1995;332(9):556-561.

2. Stookey AD, Katzel LI, Steinbrenner G, Shaughnessy M, Ivey FM. The short physical performance battery as a predictor of functional capacity after stroke. J Stroke Cerebrovasc Dis. 2014;23(1):130-135.

3. Eisner MD, Blanc PD, Yelin EH, et al. COPD as a systemic disease: impact on physical functional limitations. Am J Med. 2008;121(9) 789-796.

4. Guralnik JM. Assessing Physical Performance in the Older Patient [CD-ROM]. Bethesda, MD: National Institutes of Aging; 2013. Available from: http://www.grc.nia.nih.gov/branches/leps/sppb/. Accessed November, 2015.

5. Guralnik JM, Ferrucci L, Pieper CF, et al. Lower extremity function and subsequent disability: consistency across studies, predictive models, and value of gait speed alone compared with the short physical performance battery. J Gerontol A Biol Sci Med Sci. 2000;55(4):221-231.

6. Hall KS, McAuley E. Examining indirect associations between physical activity, function, and disability in independent and assisted living residents. J Phys Act Health. 2011;8(5):716-723.

7. Studenski S, Perera S, Wallace D, et al. Physical performance measures in the clinical setting. J Am Geriatr Soc. 2003;51(3):314-322.

8. Guralnik JM, Simonsick EM, Ferrucci L, et al. A short physical performance battery assessing lower extremity function: association with self-reported disability and prediction of mortality and nursing home admission. J Gerontol. 1994;49(2):M85-M94.

9. Penninx BW, Ferrucci L, Leveille SG, Rantanen T, Pahor M, Guralnik JM. Lower extremity performance in nondisabled older persons as a predictor of subsequent hospitalization. J Gerontol A Biol Sci Med Sci. 2000;55(11):M691-M697.

10. Short FS. Physical Performance Battery in hospitalized older adults. Gerontol. 2008;48:525-526.

11. Ostir GV, Kuo Y, Berges IM, Markides KS, Ottenbacher KJ. Measures of lower body function and risk of mortality over 7 years of follow-up. Am J Epidemiol. 2007;166(5):599-605.

12. Cesari M, Onder G, Zamboni V, et al. Physical function and self-rated health status as predictors of mortality: results from longitudinal analysis in the ilSIRENTE study. BMC Geriatr. 2008;8(1):34-42.

13. Cesari M, Kritchevsky SB, Newman AB, et al; Health, Aging and Body Composition Study. Added value of physical performance measures in predicting adverse health-related events: results from the health, aging and body composition study. J Am Geriatr Soc. 2009;57(2):251-259. 
14. Volpato S, Cavalieri M, Sioulis F, et al. Predictive value of the short Physical Performance Battery following hospitalization in older patients. J Gerontol A Biol Sci Med Sci. 2010;66(1):89-96.

15. Eisner MD, Iribarren C, Blanc PD, et al. Development of disability in chronic obstructive pulmonary disease: beyond lung function. Thorax. 2011;66(2):108-114.

16. Katz PP, Gregorich S, Eisner MD, et al. Disability in valued life activities among individuals with COPD and other respiratory conditions. J Cardiopulm Rehabil Prev. 2010;30(2):126-136.

17. Kon SS, Patel MS, Canavan JL, et al. Reliability and validity of the 4-metre gait speed in COPD. Eur Respir J. 2013;42(2):333-340.

18. Jones SE, Kon SS, Canavan JL, et al. The five-repetition sit-to-stand test as a functional outcome measure in COPD. Thorax. 2013;68(11): 1015-1020.

19. Bernabeu-Mora R, Medina-Mirapeix F, Llamazares-Herrán E, García-Guillamón G, Giménez-Giménez LM, Sánchez-Nieto JM. The Short Physical Performance Battery (SPPB) is a discriminative tool for identifying patients with COPD at risk of disability. Int J Chron Obstruct Pulmon Dis. 2015;10:2619-2626.

20. Karpman C, Depew ZS, Lebrasseur NK, Novotny PJ, Benzo RP. Determinants of gait speed in chronic obstructive lung disease. Chest. 2014;146(1):104-110.

21. Ozalevli S, Ozdena A, Itil O, Akkoclu A. Comparison of the sit-to-stand test with 6 min walk test in patients with chronic obstructive pulmonary disease. Respir Med. 2007;101(2):286-293.

22. Polkey MI, Spruit MA, Edwards LD, et al; Evaluation of COPD Longitudinally to Identify Predictive Surrogate Endpoints (ECLIPSE) Study Investigators. Six-minute-walk test in chronic obstructive pulmonary disease: minimal clinically important difference for death or hospitalization. Am J Respir Crit Care Med. 2013;187(4):382-386.

23. Benzo R, Siemion W, Novotny P, et al; National Emphysema Treatment Trial Research Group. Factors to inform clinicians about the end of life in severe chronic obstructive pulmonary disease. J Pain Symptom Manage. 2013;46(4):491-499.

24. Patel MS, Mohan D, Andersson YM, et al. Phenotypic characteristics associated with reduced short physical performance battery score in COPD. Chest. 2014;145(5):1016-1024.

25. Karpman C, Benzo RP. Gait speed as a measure of functional status in COPD patients. Int J Chron Obstruct Pulmon Dis. 2014;9:1315-1320.

26. Global Initiative for Chronic Obstructive Lung Disease (GOLD) [homepage on the Internet]. Global Strategy for the Diagnosis, Management and Prevention of COPD, Global Initiative for Chronic Obstructive Lung Disease (GOLD). 2015. Available from: http://www.goldcopd. org/. Accessed November 27, 2015.

27. O'Shea SD, Taylor NF, Paratz J. Measuring muscle strength for people with chronic obstructive pulmonary disease: retest reliability of handheld dynamometry. Arch Phys Med Rehabil. 2007;88(1):32-36.

28. American Thoracic Society (ATS). American Thoracic Society statement: guidelines for the six-minute walk test. Am J Respir Crit Care Med. 2002;166(1):111-117.

29. Miller MR, Hankinson J, Brusasco V, et al; ATS/ERS Task Force. Standardisation of spirometry. Eur Respir J. 2005;26(2):319-338.
30. Castellsagué J, Burgos F, Sunyer J, Barberà JA, Roca J. Prediction equations for forced spirometry from European origin population. Respir Med. 1998;92(3):401-407.

31. Bestall JC, Paul EA, Garrod R, Garnham R, Jones PW, Wedzicha JA. Usefulness of the Medical Research Council (MRC) dyspnea scale as a measure of disability in patients with chronic obstructive pulmonary disease. Thorax. 1999;54(7):581-586.

32. Jones PW, Harding G, Berry P, Wiklund I, Chen WH, Kline Leidy N. Development and first validation of the COPD assessment test. Eur Respir J. 2009;34(3):648-654.

33. Spruit MA, Watkins ML, Edwards LD, et al; Evaluation of COPD Longitudinally to Identify Predictive Surrogate Endpoints (ECLIPSE) study investigators. Determinants of poor 6-min walking distance in patients with COPD: the ECLIPSE cohort. Respir Med. 2010;104(6): 849-857.

34. Ruiz Comellas A, Pera G, Baena Díez JM, et al. [Validation of a Spanish short version of the Minnesota leisure time physical activity questionnaire (VREM)]. Rev Esp Salud Publica. 2012;86(5):495-508.

35. Zigmond AS, Snaith RP. The hospital anxiety and depression scale. Acta Psychiatr Scand. 1983;67(6):361-370.

36. Bjelland I, Dahl AA, Haug TT, Neckelmann D. The validity of the Hospital Anxiety and Depression Scale. An updated literature review. J Psychosom Res. 2002;52(2):69-77.

37. Tabachnick BG, Fidell LS. Using Multivariate Statistics. 6th ed. Boston: Pearson; 2013.

38. Gill TM. Assessment of function and disability in longitudinal studies. J Am Geriatr Soc. 2010;58(suppl 2):S308-S312.

39. Scarborough DM, Krebs DE, Harris BA. Quadriceps muscle strength and dynamic stability in elderly persons. Gait Posture. 1999;10(1): 10-20.

40. Hughes MA, Myers BS, Schenkman ML. The role of strength in rising from a chair in the functionally impaired elderly. J Biomech. 1996; 29(12):1509-1513.

41. Beauchamp MK, Sibley KM, Lakhani B, et al. Impairments in systems underlying control of balance in COPD. Chest. 2012;141(6): 1496-1503.

42. David Scott D, Stuartb AL, Kay D, Ebeling PR, Nicholson G, Sanders KM. Investigating the predictive ability of gait speed and quadriceps strength for incident falls in community-dwelling older women at high risk of fracture. Arch Gerontol Geriatr. 2014;58(3):308-313.

43. Shumway-Cook A, Woollacott M. Motor Control Translating Research into Clinical Practice. 3rd ed. Philadelphia, PA: Lippincott Williams and Wilkins; 2007.

44. Eisner MD, Iribarren C, Yelin EH, et al. Pulmonary function and the risk of functional limitation in chronic obstructive pulmonary disease. Am J Epidemiol. 2008;167(9):1090-1101.

45. Vittinghoff E, McCulloch CE. Relaxing the rule of ten events per variable in logistic and Cox regression. Am J Epidemiol. 2007;165(6): $710-718$.
International Journal of COPD

\section{Publish your work in this journal}

The International Journal of COPD is an international, peer-reviewed journal of therapeutics and pharmacology focusing on concise rapid reporting of clinical studies and reviews in COPD. Special focus is given to the pathophysiological processes underlying the disease, intervention programs, patient focused education, and self management protocols.
Dovepress

This journal is indexed on PubMed Central, MedLine and CAS. The manuscript management system is completely online and includes a very quick and fair peer-review system, which is all easy to use. Visit http://www.dovepress.com/testimonials.php to read real quotes from published authors. 